\title{
Polynucleotide Sequence Relatedness Among Shigella Species
}

\author{
DON J. BRENNER, G. R. FANNING, G. V. MIKLOS, and A. G. STEIGERWALT
}

Division of Biochemistry, Walter Reed Army Institute of Research, Washington, D. C. 20012

\begin{abstract}
Polynucleotide sequence relatedness in strains of Shigella species was assessed by determining the extent of reassociation in heterologous deoxyribonucleic acid preparations. Thermal elution chromatography on hydroxyapatite was used to separate reassociated nucleotide sequences from nonreassociated sequences and to determine the degree of unpaired bases within related nucleotide sequences. Almost all Shigella strains share $80 \%$ or more of their nucleotide sequences. Less than $3 \%$ of unpaired bases are present in these related sequences. The same extent of relatedness is present between Shigella and Escherichia coli strains. Strains of $S$. boydii $\mathrm{C} 13$ are highly interrelated. These strains average only about $65 \%$ relatedness to other Escherichieae. We were unable to detect preferentially high relatedness between those Shigella and E. coli strains that contain identical or related $\mathrm{O}$ antigens.
\end{abstract}

The tribe Escherichieae Bergey et al. (9) contains two genera, Escherichia Castellani and Chalmers and Shigella Castellani and Chalmers. These genera are highly related based on biochemical reactions $(8)$, serological crossreactions (8), a mino acid sequence similarity in proteins (13), and total deoxyribonucleic acid (DNA) sequence similarity (4).

The four Shigella species, $S$. boydii, $S$. dysenteriae, $S$. flexneri, and $S$. sonnei, are quite similar biochemically (10). Each species is divided into several serotypes, and many of these cross-react with Escherichia coli serotypes (8).

Shigella species show 80 to $89 \%$ DNA relatedness to $E$. coli $\mathrm{K}-12$. The thermal stability of reassociated DNA duplexes held in common between these organisms indicates less than $2 \%$ unpaired bases or divergence (4). One objective of this study was to determine the level of DNA relatedness among Shigella species compared to that between Shigella species and $E$. coli strains.

It was recently demonstrated that $E$. coli strains grouped by pathogenicity and immunoelectrophoretic mobility patterns show preferentially high intragroup DNA relatedness. A second objective of the present study was to determine whether preferentially high overall DNA relatedness is present in reactions between shigellae and $E$. coli strains that contain identical or similar $\mathrm{O}$ antigens.

\section{MATERIALS AND METHODS}

Organisms and media. The strains used in this study are listed in Table 1. Cultures of these organisms were maintained on brain heart infusion agar slants and were propagated on brain heart infusion broth. The medium employed for labeling cells has been described previously (3).

Preparation of DNA and DNA reassociation. Both unlabeled and labeled DNA were prepared, purified, and sheared as described previously $(3,4)$. Conditions for DNA reassociation and separation of singlestranded from reassociated DNA on hydroxyapatite were presented elsewhere (5). These conditions were used in this study with the following modifications.

The buffer concentration employed during incubation was increased from $0.14 \mathrm{M}$ PB to $0.28 \mathrm{M} \mathrm{PB}$ (PB $=$ phosphate buffer, an equimolar mixture of $\mathrm{NaH}_{2} \mathrm{PO}_{4}$ and $\mathrm{Na}_{2} \mathrm{HPO}_{4}, \mathrm{pH} 6.8$ ). DNA reassociates approximately 2.7 times as fast in $0.28 \mathrm{M} \mathrm{PB}$ as in $0.14 \mathrm{M} \mathrm{PB}(7)$. The amount of unlabeled DNA in the reassociation reaction was decreased from $400 \mu \mathrm{g} / \mathrm{ml}$ to $150 \mu \mathrm{g} / \mathrm{ml}$, and the reaction was carried to 100 Cots (DNA concentration $x$ time units; see reference 7). The incubation mixture was diluted in distilled water to $0.14 \mathrm{M}$ PB before being applied to hydroxyapatite. The result of these modifications is to economize on the amount of unlabeled DNA needed for each test. Control reactions indicate that completeness of reassociation is not affected by these modifications. The concentration of labeled DNA $(0.1 \mu \mathrm{g} / \mathrm{ml}$; specific activity 50,000 to 150,000 counts per min per $\mu \mathrm{g}$ ) was not changed. In control experiments the reassociation of labeled DNA in $0.28 \mathrm{M}$ PB was $2.5 \%$ or less. 
TABLE 1. Strains employed

\begin{tabular}{|c|c|}
\hline Strain & Source ${ }^{a}$ \\
\hline Bethesda 6 & $\mathrm{CDC}$ \\
\hline Edwardsiella tarda $1795-62$ & $\mathrm{CDC}$ \\
\hline Enterobacter aerogenes $1494-70$ & $\mathrm{CDC}$ \\
\hline Enterobacter liquefaciens $6136-66$ & CDC \\
\hline Escherichia coli B & WRAIR \\
\hline Escherichia coli $\mathrm{K}-12$ & $\begin{array}{l}\text { Univ. of } \\
\text { Washington }\end{array}$ \\
\hline Escherichia coli 028 & WRAIR \\
\hline Escherichia coli 0115 & SSI \\
\hline Escherichia coli 0124 & WRAIR \\
\hline Escherichia coli 0124 & SSI \\
\hline Escherichia coli 0136 & WRAIR \\
\hline Escherichia coli 0136 & SSI \\
\hline Escherichia coli 0143 & WRAIR \\
\hline Escherichia coli 0144 & WRAIR \\
\hline Escherichia coli 0147 & WRAIR \\
\hline Serratia marcescens & WRAIR \\
\hline Salmonella typhimurium LT2 & NIH \\
\hline Shigella boydii $\mathrm{Cl}$ & WRAIR \\
\hline Shigella boydii $\mathrm{C} 7$ & WRAIR \\
\hline Shigella boydii $\mathrm{C} 8$ & WRAIR \\
\hline Shigella boydii $\mathrm{C} 10$ & WRAIR \\
\hline Shigella boydii $\mathrm{C} 13$ & WRAIR \\
\hline Shigella boydii C13 1610-55 & $\mathrm{CDC}$ \\
\hline Shigella boydii C13 2045-54 & $\mathrm{CDC}$ \\
\hline Shigella boydii C13 2406-51 & $\mathrm{CDC}$ \\
\hline Shigella dy senteriae A1 & WRAIR \\
\hline Shigella dysenteriae A2 & WRAIR \\
\hline Shigella dysenteriae A3 & WRAIR \\
\hline Shigella dysenteriae A10 & WRAIR \\
\hline Shigella flexneri 2 a 24570 & S. Falkow \\
\hline Shigella flexneri 6 & WRAIR \\
\hline Shigella sonnei & WRAIR \\
\hline Shigella sonnei avirulent & WRAIR \\
\hline Shigella sonnei virulent & WRAIR \\
\hline
\end{tabular}

${ }^{a}$ Abbreviations: CDC, Center for Disease Control, Atlanta, Ga., from W. H. Ewing, G. J. Hermann, and W. J. Martin; WRAIR, Walter Reed Army Institute of Research, Washington, D.C.; SSI, Statens Serum Institute, Copenhagen, Denmark, from F. $\phi_{\text {rskov }}$ NIH, National Institutes of Health, Bethesda, Md., from $T$. Theodore.

Relative binding values were not corrected for the background reassociation of labeled DNA.

Spectrophotometric determination of genome size. The molecular complexity or genome size of bacterial DNA was determined using the technique of Gillis et al. (11) as previously described (4).

\section{RESULTS}

Relatedness data from DNA reassociation reactions followed by thermal elution chromatography on hydroxyapatite are shown in Table 2, and reactions among Escherichieae are summarized in Table 3 . With the exception of $S$. boydii C13, to be discussed below, the
Shigella strains tested showed at least $77 \%$ relatedness. We assume that each one percent of unpaired bases within a reassociated heterologous DNA duplex causes a one degree decrease in duplex thermal stability $(1,12)$. Therefore the thermal elution midpoint $\left(\Delta T_{m(e)}\right)$ values in Tables 2 and 3 indicate less than $3 \%$ unpaired bases, or divergence, present in related sequences in shigellae. In general, relatedness between species of Shigella is between 80 and $90 \%$ with $2 \%$ or less divergence. In reactions carried out at the more stringent $75 \mathrm{C}$ incubation temperature (not shown), relative binding is only slightly lower than that obtained at $60 \mathrm{C}$. This result confirms the high degree of similarity between DNA from Shigella strains. In most cases strains from one Shigella species are no more related to each other than to other species of Shigella. S. sonnei strains may be an exception based on the virtual identity of the three strains tested.

The $E$, coli strains tested here and in a previous study (4) exhibit the same high degree of relatedness to a given Shigella species as is seen between species of Shigella. Furthermore, the extent of divergence in DNA sequences shared by $E$. coli and Shigella strains is no greater than that observed in Shigella DNA heteroduplexes. It may be noted that the two separate subcultures of $E$. coli strains 0124 and 0136 gave essentially identical results with all Shigella strains. These results in effect serve to control the variability in repeated DNA isolations from a given strain.

Reactions involving Shigella species and representatives of other genera of enterobacteria are also shown in Table 2 . The degree of binding observed and the thermal lability of the related sequences indicate that extensive $\mathrm{di}$ vergence has occurred between Escherichieae and members of the tribes Edwardsielleae, Salmonelleae, and Klebsielleae. These data confirm results obtained using $E$. coli reference strains (2).

Spectrophotometric determinations of genome size obtained by comparing initial rates of DNA reassociation (11) were performed on E. coli $\mathrm{K}-12, S$. flexneri, and $S$. dysenteriae strains $\mathrm{A} 3$ and $\mathrm{A} 10$. E. coli $\mathrm{K}-12$ has a genome size of $2.56 \times 10^{y}$ daltons (4). S. flexneri has the same genome size as $E$. coli $\mathrm{K}-12$. The genomes in $S$. dysenteriae strains are about $5 \%$ (strain A 10) to $10 \%$ (strain A3) larger than that of $E$. coli K-12. It appears from the reciprocalbinding data that the $S$. boydii $\mathrm{Cl} 10$ genome is about $10 \%$ smaller than the genomes of $E$. coli $\mathrm{K}-12$ and $S$. flexneri.

The strains initially labeled in this study were 
S. boydii C10, S. flexneri 2a 24570 , and $S$. sonnei virulent. The reactions of DNA from these organisms with DNA from $S$. boydii $\mathrm{C} 13$ seemed abnormally low (68-75\%), especially since the $\Delta T_{m(e)}$ values were $6.8 \mathrm{C}$ and $7.7 \mathrm{C}$. When DNA from strain C13 was labeled, the same comparatively low extent of relatedness and comparatively low thermal stability was seen in reactions with DNA from all tested shigellae and $E$. coli strains (Table 2). Three additional $\mathrm{Cl} 3$ strains were obtained from the Center for Disease Control. DNA from the first C13 strain averaged $96 \%$ relatedness with these new $\mathrm{C} 13$ strains, whereas DNA from $E$. coli B showed an average $65 \%$ relatedness to the $\mathrm{C} 13$ strains (Table 2).

These data, together with the fact that homologous C13 reference DNA averaged $87 \%$ reassociation with a $\Delta T_{m(e)}$ of $90 \mathrm{C}$ or higher, rule against the possibility of a poor C13 DNA preparation being responsible for the low binding and thermal stability of heterologous C13 reactions.

Except for $S$. sonnei strains, virtually all shigellae share identical or reciprocal $\mathrm{O}$ antigens with one or more strains of $E$. coli (reference 8, p. 138). The average relatedness of $E$. coli strains to shigellae is shown in Table 3 . Reactions with $S$. sonnei virulent are just as high as with $S$. boydii $\mathrm{C} 10$ and $S$. flexneri 2 a 24570 . To test possible preferential relatedness between $E$. coli and Shigella strains with common or related antigens, individual strains were compared as shown in Table 4 . In no case was the reaction of an $E$. coli strain with the antigenically related Shigella strain higher than its reaction with other shigellae. In addition, the reaction of the three Shigella strains with antigenically related $E$. coli strains was no greater than reactions with $E$. coli strains with which they do not share $O$ antigens.

\section{DISCUSSION}

C13 is a rarely encountered serotype of $S$. boydii (W. H. Ewing, personal communication). DNA from the four C13 strains used in this study is almost totally related. Both in terms of total reaction and thermal stability of the related sequence, the reaction of C13 DNA with all other Escherichieae is strikingly low. C13 reference strain DNA formed extensive and stable DNA duplexes in both homologous reactions and reactions involving other $\mathrm{C} 13$ strains. These facts essentially rule out any possibility that the low related ness of C13 DNA to that of other shigellae was due to a poor $\mathrm{C} 13$
DNA preparation. Neither can one explain these data on the assumption that $\mathrm{C} 13$ strains contain abnormally large genomes, since (i) reciprocal binding data indicate that the $\mathrm{C} 13$ genome is at most 4 to $10 \%$ larger than the genomes of the other Shigella reference strains, and (ii) a difference in genome size cannot account for the substantially decreased thermal stability of the heterologous C13 DNA duplexes.

Based on our limited survey, the C13 strains seem to have conserved their gross DNA sequences while having diverged from all other Escherichieae. It is of great interest to determine whether some unknown ecological niche is responsible for this unusual pattern of evolutionary divergence and to determine whether any of the other rarely encountered Shigella seroty pes show a similar pattern.

DNAs from almost all other shigellae were $80 \%$ or more related with evidence of less than $3 \%$ divergence in related sequences. These data and selected genome size determinations fall into the same range as previously found in a much larger sampling of $E$. coli strains (4).

The three $S$. sonnei strains tested are indistinguishable based on DNA reassociation. Strains of $S$. boydii, $S$. dysenteriae, and $S$. flexneri do not exhibit preferentially high intraspecies binding as compared to interspecies binding. Furthermore, average relatedness between Shigella species and $E$. coli strains is just as high as relatedness between species of Shigella.

It must again be emphasized that these data were derived from only a few strains of each Shigella species. Within this framework, however, it is clear that, excepting $S$. sonnei, 20 to $25 \%$ of the unrelated DNA exists in strains of a given species of Shigella and that the same extent of divergence is present between species of Shigella and between shigellae and $E$. coli strains.

Preferentially high binding was not observed between two pairs of Shigella and pathogenic $E$. coli strains that not only have identical or related $\mathrm{O}$ antigens but also cause disease by similar mechanisms. This result is apparently in contrast to previous results (6) in which preferentially high binding was present among groups of $E$. coli strains prevalent in certain types of infection and whose $\mathrm{O}$ antigens have a common pattern of electrophoretic mobility. If these two pairs of strains are representative of all shigellae and $E$. coli strains with related $O$ antigens, the explanation for this result is not known. However, one must consider that the $\mathrm{O}$ antigen and pathogenicity account for a smaller 


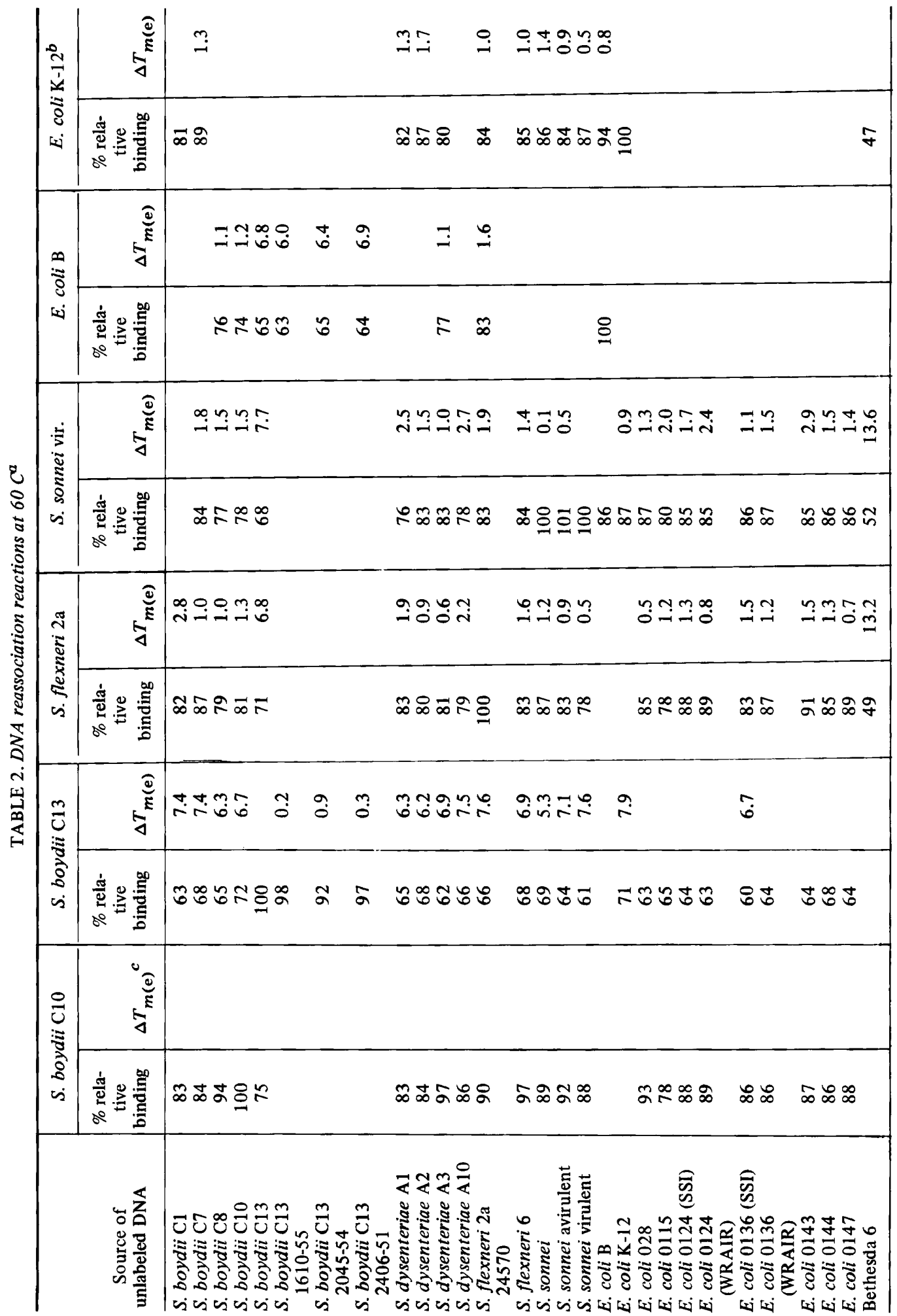




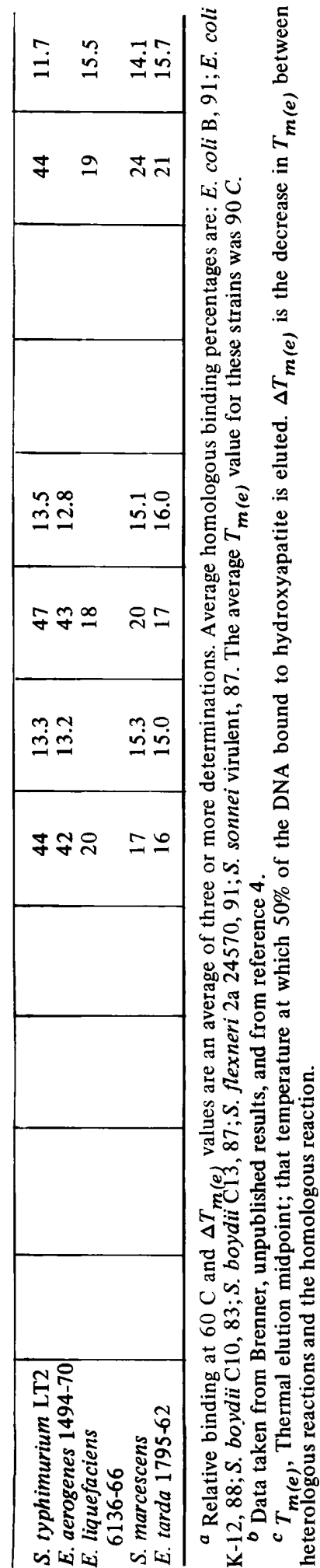

proportion of the genome in these strains than in previously tested $E$. coli strains. Therefore, these similarities cannot be detected against the background of $80 \%$ or greater total DNA relatedness. Alternatively, the preferentially high relatedness among groups of pathogenic $E$. coli strains may be due to conservation of genes other than those for $\mathrm{O}$ antigens and pathogenicity.

It has been suggested (4) that the parameters of DNA relatedness, guanine plus cytosine content, and genome size form the basis of a molecular definition of a species. $E$. coli strains form a group whose DNAs contain 48 to $52 \%$ guanine plus cytosine, have a molecular weight of $2.3 \times 10^{9}$ to $3.0 \times 10^{9}$, and show $80 \%$ or higher relative reassociation. On these bases it is difficult to distinguish between $E$. coli and Shigella species. It certainly seems that these organisms are sufficiently related to be included in the same genus. Alternatively, $\mathrm{C} 13$ strains (and possibly other strains that have not been looked at) have deviated from the mainstream of Shigella-E. coli DNA evolution while retaining the biochemical identification of the species S. boydii.

We are strongly of the opinion that polynucleotide sequence relatedness is the most reliable basis for classification. However, one cannot ignore metabolic and serological criteria for taxonomy. It is true that certain antigens are rather nonspecific, that a given antigen or biochemical reaction assays less than $0.1 \%$ of the genetic capacity of the average bacterial genome, that a negative biochemical reaction may result from just one base change in otherwise identical genes, and that widely different enzymes can catalyze the same reaction. Nevertheless, with relatively few exceptions, taxonomic groupings based on biochemical reactions and serology agree very well with DNA relatedness data.

Whether one likes it or not, practical and logical factors are quite important in considering changes in existing systems of taxonomy and nomenclature. For example, if a culture is routinely keyed out as belonging to the genus Shigella, it is both confusing and unrealistic to rename or reclassify the organism by using data not useful in the clinical laboratory. Such action would probably not change laboratory usage of the familiar name of classification. This is not to imply that changes in classification should not be made. Our intent is to urge caution and consultation with both clinical and basic researchers before recommending changes in established taxonomic groups. One alternative (or perhaps an inevitable consequence of 
TABLE 3. Summary of reassociation data

\begin{tabular}{|c|c|c|c|c|c|c|c|}
\hline \multirow[b]{2}{*}{$\begin{array}{c}\text { Source of unlabeled } \\
\text { DNA }\end{array}$} & \multicolumn{4}{|c|}{ Average $\%$ relative binding, $60 \mathrm{C}^{a}$} & \multicolumn{3}{|c|}{$\Delta T_{m(e)}, 60 \mathrm{C}^{b}$} \\
\hline & $\begin{array}{c}\text { S. boy- } \\
\text { dii } \\
\text { C10 }\end{array}$ & $\begin{array}{c}\text { S. boy- } \\
\text { dii } \\
\text { C13 }\end{array}$ & $\begin{array}{l}\text { S. flexneri } \\
\text { 2a } 24570\end{array}$ & $\begin{array}{l}\text { S. sonnei } \\
\text { virulent }\end{array}$ & $\begin{array}{c}\text { S. boy- } \\
\text { dii } \\
\text { C13 }\end{array}$ & $\begin{array}{l}\text { S. flexneri } \\
\text { 2a } 24570\end{array}$ & $\begin{array}{l}\text { S. sonnei } \\
\text { virulent }\end{array}$ \\
\hline $\begin{array}{l}\text { S. boydii } \mathrm{C} 1, \mathrm{C} 7, \mathrm{C} 8 \\
\text { and } \mathrm{C} 10 \text { strains }\end{array}$ & 87 & 67 & 82 & 80 & 7.0 & 1.5 & 1.6 \\
\hline S. boydii $\mathrm{C} 13$ strains & 75 & 96 & 71 & 68 & 0.5 & 6.8 & 7.7 \\
\hline S. dysentery strains & 88 & 65 & 81 & 80 & 6.7 & 1.4 & 1.9 \\
\hline$S$. flexneri strains & 94 & 67 & 83 & 84 & 7.3 & 1.6 & 1.7 \\
\hline S. sonnei strains & 90 & 65 & 83 & 100 & 6.7 & 1.2 & 0.3 \\
\hline$E$. coli strains $^{c}$ & 87 & 65 & 86 & 85 & 7.3 & 1.1 & 1.7 \\
\hline
\end{tabular}

${ }_{b}^{a}$ Homologous reactions are not included in average.

b See Table 2 for definition of $\Delta T_{m e}$.

$c$ The average values for the two 0124 strains and the two 0136 strains were used rather than including the separate values for each of these strains.

TABLE 4. Relatedness among strains of Shigella species and $E$. coli strains with identical or reciprocal $O$ antigens

\begin{tabular}{l|c|c|c|c|c}
\hline \multirow{2}{*}{ Source of unlabeled DNA } & \multicolumn{5}{|c}{$\%$ relative binding, 60 C } \\
\cline { 2 - 6 } & $\begin{array}{c}\text { S. boydii } \\
\text { C8 }\end{array}$ & $\begin{array}{c}\text { S. boydii } \\
\text { C10 }\end{array}$ & $\begin{array}{c}\text { S. boydii } \\
\text { C13 }\end{array}$ & $\begin{array}{c}\text { S. flexneri } \\
2 \text { a 24570 }\end{array}$ & $\begin{array}{c}\text { S. sonnei } \\
\text { virulent }\end{array}$ \\
\hline E. coli 028 (reciprocal to C13) & 82 & 93 & 63 & 85 & 87 \\
E. coli 0115 & & 78 & 65 & 78 & 80 \\
E. coli $0124^{a}$ & 83 & 89 & 64 & 89 & 85 \\
E. coli $0136^{a}$ & & 86 & 62 & 85 & 87 \\
E. coli 0143 (identical to C8) & 85 & 87 & 64 & 91 & 85 \\
E. coli 0144 & 83 & 86 & 68 & 85 & 86 \\
E. coli 0147 & 86 & 88 & 64 & 89 & 86 \\
\hline
\end{tabular}

${ }^{a}$ Two strains tested; the average value from reactions with both strains is shown.

current taxonomic trends) is one taxonomy for the purpose of defining genotypic relatedness and another for use in the laboratory. An additional alternative is to use pathotypes or other infraspecific designations for organisms that are closely related, yet require separation for clinical or other specific purposes.

\section{ACKNOWLEDGMENT}

We are extremely indebted to $S$. Formal for advice and encouragement during the course of this study and for reviewing the manuscript.

Address requests for reprints to: Dr. Don J. Brenner, Division of Biochemistry, Walter Reed Army Institute of Research, Walter Reed Army Medical Center, Washington, D. C. 20012.

\section{LITERATURE CITED}

1. Bautz, E. K. F., and F. A. Bautz. 1964. The influence of non-complementary bases on the stability of ordered polynucleotides. Proc. Natl. Acad. Sci. U.S.A. 52:1476-1481.

2. Brenner, D. J., and S. Falkow. 1971. Molecular relationships among members of the Enterobac. teriaceae. Advan. Genet, 16:81-118.

3. Brenner, D. J., G. R. Fanning, K. E. Johnson, R. V. Citarella, and S. Falkow. 1969. Polynucleotide sequence relationships among members of the Enterobacteriaceae. J. Bacteriol. 98:637-650.

4. Brenner, D. J., G. R. Fanning, F. J. Skerman, and S. Falkow. 1972. Polynucleotide sequence divergence among strains of Escherichia coli and closely related organisms. J. Bacteriol. 109:953-965.

5. Brenner, D. J., G. R. Fanning, and A. G. Steigerwalt. 1972. Deoxyribonucleic acid relatedness among species of Erwinia and between Erwinia species and other enterobacteria. J. Bacteriol. 110:12-17.

6. Brenner, D. J., G. R. Fanning, A. G. Steigerwalt, I. Ørskov, and F. Ørskov. 1972. Polynucleotide sequence relatedness among three groups of pathogenic Escherichia coli strains. Infect. Immunity 6:308-315.

7. Britten, R. J., and D. E. Kohne. 1966. Nucleotide 
sequence repetition in DNA. Carnegie Inst. Washington Yearb. 65:78-106.

8. Edwards, P. R., and W. H. Ewing. 1972. Identification of Enterobacteriaceae. Third Edition. Burgess Publ. Co., Minneapolis, Minn.

9. Ewing, W. H. 1967. Revised definitions for the family Enterobacteriaceae, its tribes and genera. Publication from the Center for Disease Control, Atlanta, Ga.

10. Ewing, W. H., J. V. Sikes, H. G. Walthen, W. J. Martin, and J. E. Jaugstetter. 1971. Biochemical reactions of Shigella. Publication from the Center for Disease Control, Atlanta, Ga.
11. Gillis, M., J. De Ley, and M. De Cleene. 1970. The determination of molecular weight of bacterial genome DNA from renaturation rates. Eur. J. Biochem. 12:143-153.

12. Laird, C. D., B. L. McConaughy, and B. J. McCarthy. 1969. On the rate of fixation of nucleotide substitutions in evolution. Nature (London) 224: 149-154.

13. Li, S., and C. Yanofsky. 1972. Amino acid sequences of fifty residues from the amino acid termini of the tryptophan synthetase $\alpha$ chains of several enterobacteria. J. Biol. Chem. 247:1031-1037. 